\title{
Perspective
}

\section{Food Taxes: A New Holy Grail?}

\author{
Ignaas Devisch* \\ Artevelde University College, University of Ghent, Belgium
}

Received: 28 June 2013, Accepted: 11 July 2013, ePublished: 11 July 2013

\section{Abstract}

In an effort to reduce the growing prevalence of overweight and obesity, food taxes have been introduced in several European countries, the so-called 'obesitax'. As yet little evidence is at hand, policy measures are being taken to counterweight the consumption of unhealthy food or the increasing diet-related diseases. Several questions need to be discussed, starting from a general perspective: can food taxes become an appropriate and just policy measure to reduce overweight and obesity and therefore increase consumer's health? The implementation of an effective and fair food tax is an exercise riddled with uncertainty. Not only is there a need for evidence on the health and economic impact of food taxes, we also have to think about a conceptual and ethical discussion concerning the balance between health imperatives and public health on the one hand, and social and ethical standards on the other hand.

\section{Keywords}

Social Inequality, Food Tax, Obesity, Responsibility

$\mathrm{I}$ $\mathrm{t}$ is a universal and well-documented phenomenon that differences in health exist between social groups. Simply put, the higher one's social position, the better one's health (1). This social inequality in health is a major issue in contemporary societies from a public health as well as from an economic and a social perspective (negative externalities in economic terms). A textbook example of this problem is the socially stratified pattern of obesity and overweight: prevalence is highest amongst low educated persons, low income families and non-Western migrants. According to the World Health Organization (WHO) (2), overweight and obesity are among this century's major health threats. Obesity and overweight are inter alia related with increased mortality, increased levels of chronic conditions and mental health conditions. There are also huge societal costs involved in terms of sick days, use of hospital beds and loss of working years. Adding to that, the number of overweight or obese people is steadily increasing, both across Europe and the US. As a result, governments struggle to find feasible and acceptable ways to cope with this problem (for Europe, e.g. the communication from the European Commission on Reducing Health Inequalities in the EU; for US, e.g. the White House Task Force on Childhood Obesity $(3,4)$.
Although a wide variety of policy measures to combat lifestyle diseases and to promote healthy diets have been advocated in the past decades, fiscal measures to regulate healthy diets such as food taxes have become most popular in recent years (5). Food taxes were implemented (but subsequently retracted) in Denmark, and are being proposed or rolled out in France, Hungary and United Kingdom. In many other countries, too, the implementation of food taxes is increasingly a matter of debate amongst public health officials and policy makers. A 'food tax' is used in public discourse as a shorthand for a government decision to levying higher taxes (through VAT or incense) on unhealthy foods to encourage healthy eating, but in reality a variety of food taxes exist. They are sometimes applied in different ways (taxing food products as a whole or specific nutrients) and not always with the intention to improve public health: revenues may or may not be applied to lower taxes on healthy food, to finance public campaigns or simply to increase revenues to the exchequer. As Caraher and Cowburn have shown in their literature review, the focus of many tax initiatives is also unclear (6). Sometimes fiscal measures are aimed at consumers, sometimes at producers; some variants are implemented in open settings (e.g. society as a whole), other taxes are set up in closed settings (e.g. schools).

It has been meticulously documented how prevailing norms on responsibility in contemporary societies have shifted over the past decades, both at the level of ideas and the level of policy practice (7). With regards to public health, people are increasingly held responsible for their lifestyle and dietary choices, even so when the causes of lifestyle diseases such as obesity are known to be multifactorial and (at least partly) determined by social and structural conditions (the so-called 'obesogenic environment'). By levying taxes on unhealthy food, a food tax embodies the idea of holding people responsible for their own welfare, a fortiori their own lifestyle, without burdening those behaving responsibly (8).

Remarkably, evidence on the effectiveness ('does it work?') of food taxes in terms of altering eating behaviour is rather limited and bound to particular, isolated settings or to one or two food products (9). The main message emerging from the literature at hand is that levying a tax on unhealthy food does seems to appear in a shift towards a healthy diet (10-12), in particular

^Corresponding author: Ignaas Devisch; Email: Ignaas.Devisch@Ugent.be 
when combined with subsidizing healthy food, but that the size of the effect might not be as large as one would expect (except when price differences are very large, e.g Steenhuis et al. (13). Some of the findings suggest that effectiveness highly depends on the design of the measure: taxing nutrients seems to work better than taxing food items, although such taxes tend to have knock-on effects on nutrients beyond those targeted $(14,15)$. In contrast, there is also evidence for a substitution effect: consumers may respond to price increases by switching to other unhealthy foods, thus canceling potential health effects (16).

Illustrating the uncertainty with regards to the effect of food taxes, a systematic review of earlier (mainly lower quality) studies concluded that taxes influence consumption in the intended direction, but that the degree of the predicted effect varies widely (17). All in all, evidence is scattered and more systematic research is clearly needed to genuinely establish the effect of food taxes on dietary behaviour $(6,9,18,19)$. More evidence is available regarding the effect of fiscal measures on reducing tobacco and alcohol consumption (20). Yet, food is not readily comparable with alcohol and tobacco: while fiscal measures aim to discourage alcohol and tobacco consumption, in the case of food they should focus on changing diet instead of discouraging eating.

Irrespective of its effectiveness, food taxes may have undesirable consequences from an ethical and social point of view. A food tax is a 'catch-all measure' aimed at reducing unhealthy behaviour at the aggregate population-level (i.e. a welfarist approach); hence neglecting the social differentiation of a healthy lifestyle. Indeed, it has been demonstrated that there is not only a steep social gradient in the prevalence of lifestyle diseases but also in dietary behaviour: disadvantaged socio-economic groups have less healthy dietary customs (21). Because lower income groups spend a greater share of their disposable income on food, a fiscal measure such as a food tax has a regressive impact on the income distribution. In so far as food taxes reinvigorate income inequality due to its regressive nature, it might actually exacerbate rather than mitigate health inequalities as well. A food tax might also be ethically problematic because it overlooks the fact that

Table 1. Food taxes: some pros and cons

\begin{tabular}{|c|c|}
\hline Pros & Cons \\
\hline $\begin{array}{l}\text { The healthy choice is now the } \\
\text { expensive choice }\end{array}$ & $\begin{array}{l}\text { Potential discrimination of low } \\
\text { income people }\end{array}$ \\
\hline $\begin{array}{l}\text { Price is an important } \\
\text { determinant in food choice }\end{array}$ & $\begin{array}{l}\text { Consumers may respond to price } \\
\text { increases by switching to other } \\
\text { unhealthy foods }\end{array}$ \\
\hline $\begin{array}{l}\text { Price is already an important } \\
\text { marketing tool }\end{array}$ & $\begin{array}{l}\text { Relationship consumption-health is a } \\
\text { very complex one }\end{array}$ \\
\hline $\begin{array}{l}\text { Subsidies on healthy foods have } \\
\text { undesired side-effects }\end{array}$ & Do we know what is healthy? \\
\hline Food taxes seem effective & $\begin{array}{l}\text { 'Catch-all measure' which is doomed } \\
\text { to fail }\end{array}$ \\
\hline
\end{tabular}

overweight and obesity are the results of a myriad of factors: an emphasis on personal responsibility might disregard these other determinants and may contribute to scapegoating those groups who are expected to benefit the most from government intervention. As argued by Ten Have et al. (22), awareness of the ethical issues at stake is crucial for policy makers and public health officials involved in the design and implementation of measures to prevent overweight and obesity.

Obviously, one cannot resume this whole debate in a few lines, but at least it can be interesting to briefly outline some of the pro's and con's of food taxes as they are framed today (see Table 1).

Given all this, one should also be aware of public attitudes regarding food taxes. The success of a government intervention not only depends on its actual impact, but also on the willingness of the public to accept it. Given the social stratified pattern of lifestyle diseases and the possible social impact of food taxes, are people willing to accept food taxes? We know from the Eurobarometer survey that $53 \%$ of EU citizens are in favour of increasing taxes on tobacco products. Similar evidence on unhealthy food and food taxes is scarce. To date, there are only few studies that have investigated people's attitudes on the appropriateness of government proposals to combat obesity in the US $(23,24)$. Barry and colleagues, for instance, established that views on government intervention are influenced by prevailing views on obesity. Consequently, in a societal context where more emphasis is put on personal responsibility for one's lifestyle, a fortiori for being obese, it could very well be the case that people's attitudes on government proposals are similarly influenced. To our knowledge, no studies on attitudes on food taxes in a EU-context exist, and data on people's views on government intervention in the context of health and social inequalities is lacking altogether. Given the social stratification in health and lifestyle and the fact that people are differentially affected by food taxes, do attitudes and the willingness to accept food taxes differ across socio-economic groups too?

In sum, the implementation of an effective and fair food tax is an exercise riddled with uncertainty. Not only there is a need for evidence on the health and economic impact of food taxes, there is also need for a conceptual and ethical discussion concerning the balance between health imperatives and public health on the one hand, and social and ethical standards on the other hand. Developing an incentive to stimulate healthier diets and a more balanced lifestyle is not only a matter of 'will it work' but also of 'do we want it'. Scientific research has to include these kinds of questions if it really aims to be innovative. Far more than a technical procedure, the development of a food tax is a matter of equal opportunities, responsibility, justice and respect for autonomy.

\section{Ethical issues}

Not applicable.

\section{Competing interests} None.

Author's contribution

ID is the single author of the manuscript.

\section{References}

1. Lundberg O, Lahelma E. Nordic health inequalities in the European context. In: Kautto M, Fritzell J, Hvinden B, Kvist J, Uusitalo H, eds. Nordic Welfare States in the European Context. Routledge: London \& New York; 2001. p. 42-65.

2. WHO. Obesity: preventing and managing the global epidemic. WHO: Geneva; 2000.

3. White House Task Force on Childhood Obesity. Solving the problem of childhood obesity within a generation. Report to the president. 
Washington, 2010.

4. European Commission. Solidarity In Health: Reducing Health Inequalities in the EU. SEC(2009) 1396, Brussels, 2009.

5. Alemanno A, Carreño I. Fat taxes in the EU: between fiscal austerity and the fight against obesity. European Journal of Risk Regulation 2011; 4: 571-6.

6. Caraher M, Cowburn G. Taxing food: implications for public health nutrition. Public Health Nut 2005; 8: 1242-9.

7. Cantillon B, Van Lancker W. Solidarity and reciprocity in the social investment state: what can be learned from the case of Flemish school allowances and truancy? J Soc Policy 2012; 41: 657-75.

8. Brownell KD, Kersh R, Ludwig DS, Post RC, Puhl RM, Schwartz MB, et al. Personal Responsibility And Obesity: A Constructive Approach to a Controversial Issue. Health Aff (Millwood) 2010; 29: 379-87.

9. Andreyeva T, Long MW, Brownell KD. The impact of food prices on consumption: a systematic review of research on price elasticity of demand for food. Am J Public Health 2010; 100: 216-22.

10. Epstein LH, Dearing KK, Paluch RA, Roemmich JN, Cho D. Price and maternal obesity influence purchasing of low- and high-energydense foods. Am J Clin Nutr 2007; 86: 914-22.

11. French SA. Pricing effects on food choices. J Nutr 2003; 133: 841-3. 12. Herman DR, Harrison GG, Afifi AA, Jenks E. Effect of a targeted subsidy on intake of fruits and vegetables among low-income women in the Special Supplemental Nutrition Program for Women, Infants, and Children. Am J Public Health 2008; 98: 98-105.

13. Steenhuis IHM, Waterlander WE, de Mul A. Consumer food choices: the role of pricing and pricing strategies. Public Health Nutr 2011; 14: 2220-6.

14. Jensen JD, Smed S. Cost-effective design of economic instruments in nutrition policy. Int J Behav Nutr Phys Act 2007; 4: 10.

15. Mytton O, Gray A, Rayner M, Rutter H. Could targeted food taxes improve health? J Epidemiol Community Health 2007; 61: 689-94. 16. Faulkner GE, Grootendorst P, Nguyen VH, Andreyeva T, ArbourNicitopoulos K, Auld MC, et al. Economic instruments for obesity prevention: results of a scoping review and modified Delphi survey. Int $J$ Behav Nutr Phys Act 2011; 8: 109.

17. Thow AM, Jan S, Leeder S, Swinburn B. The effect of fiscal policy on diet, obesity and chronic disease: a systematic review. Bull World Health Organ 2010; 88: 609-14.

18. Grunert KG, Wills JM. A review of European research on consumer response to nutrition information on food labels. J Public Health 2007; 15: 385-99.

19. Nnoaham KE, Sacks G, Rayner M, Mytton O, Gray A. Modelling income group differences in the health and economic impacts of targeted food taxes and subsidies. Int J Epidemiol 2009; 38: 1324-33.

20. Jha P, Chaloupka FJ, Corrao M, Jacob B. Reducing the burden of smoking world-wide: effectiveness of interventions and their coverage. Drug Alcohol Rev 2006; 25: 597-609.

21. Irala-Estévez JD, Groth $M$, Johansson L, Oltersdorf U, Prättälä R, Martínez-González MA. A systematic review of socio-economic differences in food habits in Europe: consumption of fruit and vegetables. Eur J Clin Nutr 2000; 54: 706-14.

22. Have MT, van der Heide A, Mackenbach JP, de Beaufort ID. An ethical framework for the prevention of overweight and obesity: a tool for thinking through a programme's ethical aspects. Eur $J$ Public Health 2013; 23: 299-305.

23. Barry CL, Brescoll VL, Brownell KD, Schlesinger M. Obesity Metaphors: How Beliefs about the Causes of Obesity Affect Support for Public Policy. Milbank Q 2009; 87: 7-47.

24. Oliver JE, Lee T. Public Opinion and the Politics of Obesity in America. J Health Polit Policy Law 2005; 30: 923-54. 